\title{
Preventive application of an entomopathogenic fungus in cover crops for wireworm control
}

\author{
Sina Alexandra Rogge · Johanna Mayerhofer • Jürg Enkerli • Sven Bacher • \\ Giselher Grabenweger
}

Received: 16 September 2016/Accepted: 27 April 2017/Published online: 12 May 2017

(C) The Author(s) 2017. This article is an open access publication

\begin{abstract}
Efficacy of the Metarhizium brunneum Petch (Hypocreales: Clavicipitaceae) strain ART2825 for control of wireworms (Agriotes obscurus (L.), Coleoptera: Elateridae) was examined in a semi-field pot experiment. Pots were treated in late summer during sowing of spring oat as a cover crop. Survival of wireworms was assessed four weeks after their release in October 2013, and 30 weeks after release in April 2014. Viability and persistence of the fungus was determined by counting colony forming units from substrate samples and microsatellite analyses of recovered Metarhizium isolates. The number of colonies detected in the substrate in October 2013 increased with increasing concentrations of applied
\end{abstract}

Handling Editor: Nicolai Meyling.

Electronic supplementary material The online version of this article (doi:10.1007/s10526-017-9816-x) contains supplementary material, which is available to authorized users.

S. A. Rogge - J. Mayerhofer · J. Enkerli .

G. Grabenweger $(\square)$

Agroscope, Institute for Sustainability Sciences, Zurich, Switzerland

e-mail: giselher.grabenweger@agroscope.admin.ch

\section{S. A. Rogge}

Institute for Phytopathology and Applied Zoology, JustusLiebig-Universität, Giessen, Germany

S. Bacher

Department of Biology, University of Fribourg, Fribourg, Switzerland conidia, and no significant reduction was observed at the second evaluation date in April 2014. Increasing conidia application rates significantly increased mycosis and reduced wireworm survival, to a level comparable to that of treatment using insecticide-coated oat seeds. The preventive application of M. brunneum conidia to reduce wireworm populations in cover crops, preceding a damage-sensitive crop like potatoes, may be a promising biocontrol strategy.

Keywords Coleoptera E Elateridae $\cdot$ Hypocreales · Clavicipitaceae $\cdot$ Arable crops $\cdot$ Potato $\cdot$ Biological control

\section{Introduction}

Wireworms are the soil dwelling larvae of click beetles (Coleoptera: Elateridae) and several species, including those in the genus Agriotes Eschscholtz, are major pests in the northern hemisphere. They feed on the roots, shoots, tubers and bulbs of many arable and vegetable crops, including maize and other cereals, potatoes and carrots (reviewed in Parker and Howard 2001; Ritter and Richter 2013; Traugott et al. 2015). In many of these crops, wireworms are not necessarily the most destructive insects, but are among the most difficult to control, particularly because of their long life cycle and overlapping generations, their polyphagous nature and their adaption to a wide range of 
agricultural ecosystems, including grassland and arable crops (Furlan 1998; Ritter and Richter 2013; Sonnemann et al. 2014; Sufyan et al. 2014; Traugott et al. 2013, 2015). Wireworms are also able to react quickly to changes in abiotic conditions with vertical migration to depths of $50 \mathrm{~cm}$ or more (Fisher et al. 1975; Furlan 1998, 2004; Schaerffenberg 1942). This behaviour often reduces the efficacy of short-term control attempts, which are typically applied to upper soil layers.

Chemical control of wireworms has been most successful with persistent insecticides, like organochlorines, organophosphates, carbamates and phenylpyrazols (reviewed in Barsics et al. 2013; Traugott et al. 2015; Vernon and van Herk 2013), some of which provide sufficient control for several seasons after a single application (Vernon et al. 2009, 2013). As a result, the preventive application of cereal seeds coated with phenylpyrazol became widely adapted in some European countries, the goal being to reduce wireworm populations and the risk of damage in subsequent sensitive crops like potatoes (Jossi 2001). Pre-planting of organochlorine-coated wheat seeds as a catch crop before planting of potatoes has also been shown to reduce wireworm damage to potatoes in experiments in Canada (Vernon et al. 2016). However, this control strategy was later abandoned when the insecticide was de-registered.

The ban or withdrawal of many of these widely used soil insecticides and the trend to more conservative soil cultivation techniques led to both an increase of wireworm populations and limitation of the options for their control (Barsics et al. 2013; Jedlička and Frouz 2007; Ritter and Richter 2013; Vernon et al. 2008, 2016). This stimulated research aimed at the development of ecologically acceptable control methods (Ester and Huiting 2007; Kabaluk et al. 2005; Kleespies et al. 2013; Kölliker et al. 2011; Ladurner et al. 2009). Among the natural enemies of wireworms, entomopathogenic fungi (EPF), especially those in the genus Metarhizium Sorokin (Hypocreales: Clavicipitaceae), are currently regarded as the most promising for wireworm control (Ansari et al. 2009; Eckard et al. 2014; Kabaluk 2007; Kabaluk and Ericsson 2007; Kölliker et al. 2011).

Here we tested the potential to adapt the strategy of applying control measures against wireworms to a crop preceding a sensitive crop like potatoes, with the use of insecticide-coated seeds of cereals replaced by soil application of Metarhizium brunneum Petch conidia. We set up a pot experiment with artificial wireworm infestation to determine whether the fungus persisted in a cover crop in early autumn and in the following spring, as this would be necessary to control wireworms in advance of the crop targeted for protection. We also assessed the influence of treatments with $M$. brunneum conidia on recapture, survival and mycosis of previously released wireworms.

\section{Materials and Methods}

Fungal inoculum and host insects

M. brunneum strain ART2825 was isolated in 2007 from an infected Agriotes obscurus larva in the rearing facility at Agroscope in Zurich, Switzerland. The strain has shown high virulence towards larvae of $A$. obscurus and A. lineatus (Eckard et al. 2014; Kölliker et al. 2011). After a host passage, the fungus was cultivated on a selective medium containing antibiotics and dodine (Strasser et al. 1996). Conidia harvested from Petri dishes were used for massproduction of fungus colonised barley kernels (FCBKs) (Aregger 1992). Number of conidia per gram of FCBKs was determined by shaking samples in $0.1 \%(\mathrm{v} / \mathrm{v})$ aqueous Tween ${ }^{\circledR} 80$ and counting the resulting conidia densities with a haemocytometer. Germination rate was examined by plating approximately 300 conidia on selective media and counting colony forming units (CFUs) after incubation for two weeks at $23{ }^{\circ} \mathrm{C}$ in the dark.

Agriotes obscurus larvae used in the experiment originated from a laboratory livestock established according to Kölliker et al. (2009). Larvae used in the experiment were about one year old and had reached at least the 7th larval stage (minimum width of head capsule $1.16 \mathrm{~mm}$ according to Klausnitzer 1994).

\section{Experimental set-up}

A semi-field pot experiment was set up in an experimental bed at Agroscope in Zurich, Switzerland $\left(47^{\circ} 25^{\prime} 40.13^{\prime \prime} \mathrm{N}, 8^{\circ} 30^{\prime} 58.10^{\prime \prime} \mathrm{E}\right)$. Pots ( $28 \mathrm{~cm}$ diameter and $24 \mathrm{~cm}$ height, surface area $615 \mathrm{~cm}^{2}$ ) were left above ground and watered as needed. They were filled with $14 \mathrm{~kg}$ of a mixture of field soil $(32.5 \%$ clay, 
$28.8 \%$ silt, $43.7 \%$ sand, $\mathrm{pH} 7.78)$ and sand (3:1 v:v). Pots were arranged in a randomized complete block design, with six blocks, six treatments, and two pots per treatment in each block, to enable sub-sampling of all treatments at two different dates (see below).

FCBKs were applied in mid-August 2013 in four different concentrations, $0.05,0.5,5$ and $50 \mathrm{~g}$ per pot, corresponding to a field application rate of $8-8000 \mathrm{~kg}$ of FCBKs or an estimated concentration of $10^{12}-10^{15}$ conidia per hectare. FCBKs were thoroughly mixed into the upper $10 \mathrm{~cm}$ of the pot substrates with a flower rake. Subsequently, 30 kernels of spring oat (variety "Expander", ASS, Moudon, Switzerland) were sown per pot $\left(=150 \mathrm{~kg} \mathrm{ha}^{-1}\right)$. We included two controls without FCBKs: in the first, oat seeds of the same variety coated with Regent ${ }^{\circledR}$ TS (BASF, $500 \mathrm{~g} \mathrm{l}^{-1}$ Fipronil at a rate of $100 \mathrm{ml}$ per $100 \mathrm{~kg}$ of seeds) were planted as an insecticide treatment, and in the second, pots with untreated spring oat served as control. Two weeks after set up, when oat seedlings reached the three-leaf stage. Seven lab-reared Agriotes obscurus were released per pot.

\section{Data collection and analysis}

The first sub-sample of 36 pots was evaluated at the beginning of October 2013, six weeks after application of FCBKs and four weeks after wireworm release. This presumably coincided with the end of the wireworms' seasonal activity period, when decreasing temperatures drove them to deeper substrate layers for hibernation. The second sub-sample of pots was analysed in April 2014, 32 weeks after application and 30 weeks after wireworm release, which corresponded to the time point suitable for potato planting in central Europe.

The substrate of each pot was thoroughly examined to recapture released wireworms or cadavers. Alive and dead individuals were transferred singly into separate cups filled with peat, provided with a carrot slice as food source, and incubated at $23{ }^{\circ} \mathrm{C}$ and $75 \%$ $\mathrm{RH}$ in the dark for six weeks. Wireworms with a healthy appearance and normal escaping behaviour after six weeks of incubation (negative phototaxis, quickly burrowing into the substrate upon replacement into cups) were counted as survivors. Only cadavers showing infection with Metarhizium spp., i.e. outgrowth of white mycelium from intersegmental integuments and formation of green conidia layers, were counted as mycosed (=killed by the FCBK treatment). Where mycosed cadavers were found, one Metarhizium spp. isolate per pot was obtained by dilution plating. Isolates were maintained on selective medium plates at $23{ }^{\circ} \mathrm{C}$ in the dark.

Abundance of the fungus in the substrate was assessed by counting the number of CFUs per gram of substrate as described in previous studies (Kessler et al. 2003; Pilz et al. 2010). Following recapture of wireworms, five soil portions of about $10 \mathrm{~g}$ were taken from the substrate of each pot using a spoon, combined in a plastic bag, and mixed thoroughly. A sub-sample of $20 \mathrm{~g}$ per pot was suspended in $100 \mathrm{ml}$ of a sodium pyrophosphate solution $\left(1.8 \mathrm{~g} \mathrm{l}^{-1} \mathrm{Na}_{4} \mathrm{P}_{2} \mathrm{O}_{7} \cdot 10 \mathrm{H}_{2} \mathrm{O}\right)$ and shaken in an Erlenmeyer flask for four hours at $120 \mathrm{rpm}$. After sedimentation for five seconds, aliquots of $100 \mu \mathrm{l}$ of the supernatant were plated on each of three Petri dishes with selective medium. Petri dishes were incubated at $23{ }^{\circ} \mathrm{C}$ and $75 \% \mathrm{RH}$ in the dark. CFUs were counted after ten days and numbers of CFUs per gram soil substrate were calculated. For analysis, we used the mean of the three Petri dishes from each pot. Five and four single colonies were randomly selected from Petri dishes of control and insecticide treatments (soil samples) of the second evaluation date for molecular genetic analyses. They were transferred to selective medium plates and maintained at $23{ }^{\circ} \mathrm{C}$ in the dark.

Wireworm recapture, survival and mycosis rates were analysed with generalised linear mixed-effect models with rates (as binary variable: positives vs. negatives) as response variable and the number of FCBKs per pot (log-transformed), the harvest date (autumn vs. spring), their interaction, and the presence of insecticide (only in one of the controls) as explanatory variables. To allow interpretation of the interaction term, the numerical variable "number of FCBKs per pot" was scaled (i.e. centred on the mean and divided by its SD; Schielzeth 2010). We assumed underlying binomial distributions and used a logit link function. Numbers of CFUs per gram soil substrate were analysed with a linear mixed model with the amount of FCBKs per pot (scaled), the harvest date (autumn vs. spring), and their interaction as explanatory variables. Here, insecticide treated pots were excluded from the analysis. In all models, we included the treatment pair nested within blocks as random effects. All statistical analyses were performed with RStudio (Version 1.0.136, RStudio 
Inc., 2016) and $\mathrm{R}$ (Version 3.3.2, $\mathrm{R}$ Development Core Team 2016) using the lme 4 package (version 1.1-12; Bates et al. 2015).

Identification of re-isolated fungal strains

One single colony per recovered Metarhizium isolate was transferred into liquid complete medium (Riba et al. 1986) and incubated in an Erlenmeyer flask at $150 \mathrm{rpm}$ for three days. The mycelium was harvested by filtration (Enkerli et al. 2001) and frozen at $-70{ }^{\circ} \mathrm{C}$. Frozen mycelium was lyophilized and homogenized with a FastPrep FP120 homogenizer (MP Biomedicals, Santa Ana, CA, USA) using $0.15 \mathrm{~g}$ of glass beads $\left(1 \mathrm{~mm}\right.$ diameter) at a speed of $6 \mathrm{~m} \mathrm{~s}^{-1}$ for $10 \mathrm{~s}$. Genomic DNA was extracted using the NucleoSpin Plant II DNA extraction kit according to the manufacturer's protocol (Macherey-Nagel, Germany).

Microsatellite marker analysis

Twelve microsatellite markers were used to compare genotypes of the collected isolates (Enkerli et al. 2005; Oulevey et al. 2009). Multiplex PCRs were performed with four sets of three markers each (set 1: Ma2049, Ma2060, Ma2069, annealing temperature $58{ }^{\circ} \mathrm{C}$; set 2: Ma2065, Ma2098, Ma2269, annealing temperature $58{ }^{\circ} \mathrm{C}$; set 3: Ma142, Ma417, Ma2224, annealing temperature $56{ }^{\circ} \mathrm{C}$; set 4: Ma097, Ma195, Ma2077, annealing temperature $50{ }^{\circ} \mathrm{C}$ ) in reaction volumes of $20 \mu \mathrm{l}$. Reactions contained $10 \mathrm{ng}$ genomic DNA, $5 \times$ GoTaq $^{\circledR}$ Flexi Reaction Buffer and 0.25 units of GoTaq $^{\circledR}$ Flexi DNA Polymerase (Promega, WI, USA), 4 (sets 1 and 2) or 3 (sets 3 and 4) $\mathrm{mM}$ $\mathrm{MgCl}_{2}$ (Oulevey et al. 2009), $0.2 \mu \mathrm{M}$ of each dNTP and $0.2 \mathrm{mM}$ forward and labelled reverse primer (FAM and HEX, Microsynth, Switzerland; NED, Applied Biosystems, CA, USA). Touch-down PCR consisted of $2 \mathrm{~min}$ initial denaturation at $94{ }^{\circ} \mathrm{C}$ followed by 12 cycles of touch-down amplification consisting of $30 \mathrm{~s}$ at $94{ }^{\circ} \mathrm{C}, 60 \mathrm{~s}$ at multiplex specific annealing temperature (see above) plus $12{ }^{\circ} \mathrm{C}$ with a decrease of $1{ }^{\circ} \mathrm{C}$ per cycle, and $60 \mathrm{~s}$ at $72{ }^{\circ} \mathrm{C}$. Subsequently, 22 cycles of $30 \mathrm{~s}$ at $94{ }^{\circ} \mathrm{C}, 60 \mathrm{~s}$ at multiplex specific annealing temperature and $60 \mathrm{~s}$ at $72{ }^{\circ} \mathrm{C}$ were performed. The amplification was terminated with a final elongation at $72{ }^{\circ} \mathrm{C}$ for $15 \mathrm{~min}$. Amplified DNA-fragment sizes (allele sizes) were determined on an ABI $3500 \times$ L Genetic Analyzer
(Applied Biosystems, CA, USA) using $50 \mathrm{~cm}$ capillaries, POP-7 polymer and GeneScan ${ }^{\mathrm{TM}}$ 400HD ROX $^{\mathrm{TM}}$ size standard. A Swiss strain of M. brunneum (ARSEF 7524) was used as reference for allele sizes. Analysis of data was performed using GeneMarker software version 2.4.0 (SoftGenetics, PA, USA).

\section{Results}

Abundance of Metarhizium CFUs in the substrate

Evaluation of pot substrates revealed the presence of Metarhizium colonies in every treatment, including the untreated control and the insecticide treatment (Table 1). The number of CFUs detected increased significantly with the concentration of conidia applied, but there was no difference between the collection dates (Table 2).

Wireworm recapture, survival and mycosis

Recapture rates of wireworms (alive and dead) were not influenced by FCBK treatments (Table 3a), but significantly fewer wireworms were recaptured from insecticide-treated pots (Fig. 1 shows the first evaluation date). Recapture rates were also significantly different between collection dates. An average wireworm recapture rate of $81 \%$ (5.6 \pm 1.2 individuals out of seven released) was achieved with the first subsample, evaluated in October 2013, four weeks after releasing wireworms. This rate dropped to an average of only $42 \%(2.9 \pm 1.9$ individuals out of seven released) in the second sub-sample, evaluated in April 2014, 30 weeks after wireworm release.

More than $33 \%$ of the wireworms recaptured at the first collection date died during laboratory incubation following recapture, mainly those from the insecticide treatment and the higher concentration fungal treatments (Fig. 2). Consequently, overall survival of wireworms after incubation showed a different pattern to that of wireworm recapture. Increasing concentrations of FCBK treatments clearly exhibited a negative effect on wireworm survival (Table 3b). This effect was similar at both collection dates, although less pronounced at the second collection in April 2014, as the significant interaction term indicates. The impact of the insecticide treatment was still significant and comparable to that of the higher-concentration FCBK treatments. 
Table 1 Mean number \pm SE of CFUs (colony forming units) per gram pot substrate six weeks (first evaluation date, early autumn) and 32 weeks (second evaluation date, spring) after application

\begin{tabular}{llrrr}
\hline Treatment & Field concentration & Number of applied conidia per gram substrate & \multicolumn{2}{l}{$\begin{array}{l}\text { Number of CFUs recovered per gram } \\
\text { substrate }\end{array}$} \\
\cline { 3 - 5 } & & & First evaluation & Second evaluation \\
\hline Control & Ambient & 0 & $25 \pm 17$ & $28 \pm 11$ \\
Insecticide & $50 \mathrm{~g}^{2}$ Fipronil/100 kg seeds & 0 & $70 \pm 40$ & $164 \pm 134$ \\
FCBK 1 & $10^{12}$ conidia ha $^{-1}$ & 400 & $153 \pm 55$ & $456 \pm 248$ \\
FCBK 2 & $10^{13}$ conidia ha $^{-1}$ & 4000 & $2467 \pm 475$ & $3414 \pm 1366$ \\
FCBK 3 & $10^{14}$ conidia ha $^{-1}$ & 40,000 & $20,414 \pm 6554$ & $10,072 \pm 3946$ \\
FCBK 4 & $10^{15}$ conidia ha $^{-1}$ & 400,000 & $182,945 \pm 81,717$ & $137,514 \pm 68,259$ \\
\hline
\end{tabular}

FCBK fungus colonised barley kernels; the number of applied conidia per gram of substrate was estimated based on a mean yield of $1.2 \times 10^{8}$ conidia per gram of FCBKs applied to $14 \mathrm{~kg}$ of pot substrate

Table 2 Coefficients, SE, z-values and p-values from a linear mixed effects model for the number of fungal colonies detected in pot substrates six weeks (first evaluation date) and 32 weeks (second evaluation date) after application. Conidia $=$ conidia concentration applied per gram of pot substrate

\begin{tabular}{lrlrl}
\hline & \multicolumn{1}{l}{ Value } & \multicolumn{1}{l}{ SE } & z-value & $p$-value \\
\hline (Intercept) & 52,104 & 28,945 & 1.80 & 0.083 \\
Conidia & 89,604 & 28,780 & 3.11 & 0.005 \\
Date & $-10,904$ & 17,536 & -0.62 & 0.539 \\
Conidia $\times$ date & $-17,728$ & 17,684 & -1.00 & 0.325 \\
\hline
\end{tabular}

The main cause of mortality for all but the insecticide treatment, where no mycosed larvae were found, was Metarhizium mycosis (Fig. 3). Treatments with higher FCBK concentrations produced a significantly greater number of mycosed cadavers (Table 3c). The number of mycosed cadavers retrieved from the second sub-sample was very low (eight mycosed cadavers from a total of 105 recaptured individuals) and, correspondingly, the model showed a significant effect of evaluation date.

\section{Identification of re-isolated Metarhizium strains}

At the first evaluation date, 24 out of 36 pots yielded at least one mycosed wireworm cadaver. Metarhizium was isolated from one cadaver per pot, resulting in 24 isolates. At the second evaluation date, seven mycosed cadavers were detected in the pot substrate of two treatments $\left(10^{13}\right.$ and $10^{14}$ conidia ha $\left.^{-1}\right)$ only, and $\mathrm{Me}$ tarhizium was isolated from each cadaver. Additionally,
Table 3 a-c Coefficients, SE, z- and p-values from generalised linear mixed effects models for the number of (a) recaptured, (b) surviving, and (c) mycosed wireworms four weeks (first evaluation date) and 30 weeks (second evaluation date) after release; FCBK = concentration of fungus colonized barley kernels applied; the insecticide treatment was excluded from the analysis of wireworm mycosis (3c)

\begin{tabular}{lrrrr}
\hline & Estimate & SE & z-value & $p$-value \\
\hline a & & & & \\
(Intercept) & 3.76 & 0.43 & 8.67 & $<0.001$ \\
FCBK & -0.39 & 0.35 & -1.14 & 0.253 \\
Date & -1.97 & 0.23 & -8.67 & $<0.001$ \\
Insecticide & -1.30 & 0.31 & -4.16 & $<0.001$ \\
FCBK $\times$ date & -0.08 & 0.21 & -0.40 & 0.69 \\
& & & & \\
b & & & & \\
(Intercept) & -0.31 & 0.35 & -0.90 & 0.369 \\
FCBK & -1.61 & 0.44 & -3.68 & $<0.001$ \\
Date & -0.05 & 0.21 & -0.23 & 0.815 \\
Insecticide & -1.96 & 0.37 & -5.34 & $<0.001$ \\
FCBK $\times$ date & 0.51 & 0.26 & 2.00 & 0.046 \\
& & & & \\
c & & & & 0.014 \\
(Intercept) & 1.40 & 0.57 & 2.45 & 0.008 \\
FCBK & 1.59 & 0.60 & 2.66 & 0.001 \\
Date & -2.05 & 0.45 & -4.54 & $<06$ \\
FCBK $\times$ date & -0.41 & 0.46 & -0.91 & 0.366 \\
\hline
\end{tabular}

at the second evaluation date, five Metarhizium isolates were randomly chosen from substrate samples of the untreated control and four isolates from the insecticide treatment, to check for the natural presence of the $M$. brunneum strain applied during the experiment. 
Fig. 1 Number of recaptured A. obscurus larvae at the first evaluation date in October 2013, four weeks after release. Boxes show the 1st (bottom line), 2nd (median, bold line), and 3rd (top line) quartiles of the data distribution, whisker ends represent the lowest and the highest data point within the 1.5 interquartile range of the lower and the upper quartile, respectively. Seven larvae were released per pot

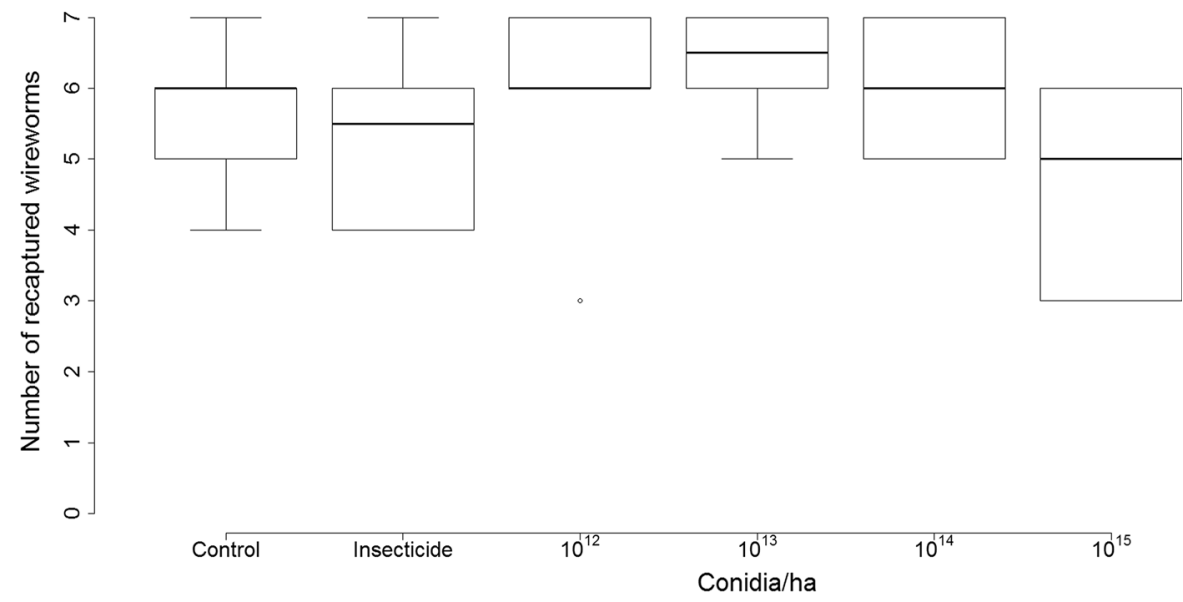

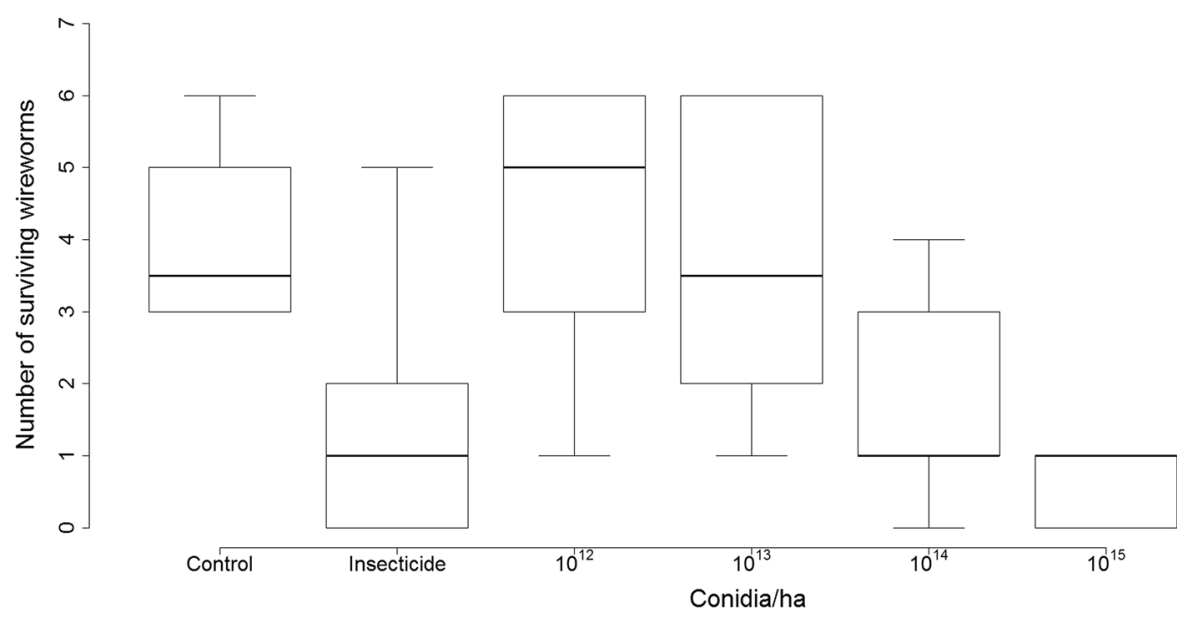

Fig. 2 Number of surviving A. obscurus larvae per pot in November 2013, recaptured from pots four weeks after release and incubated individually in peat-filled cups for another six weeks. Boxes show the 1st (bottom line), 2nd (median, bold

Microsatellite marker analyses allowed discrimination of nine different genotypes among the 40 isolates (31 isolates from cadavers and nine from soil samples, Table 4, supplementary Table S1). All isolates obtained from wireworm cadavers of fungal treatments displayed a genotype identical to the genotype of the applied strain (ART2825), irrespective of conidia concentration and evaluation date (Table 4). In contrast, genotypes of isolates obtained from four cadavers collected from the untreated control were different from the genotype of the applied strain. Nevertheless, analysis of the isolates from substrate samples revealed that the strain used for FCBK production was also present naturally in control and insecticide treatments. line), and 3rd (top line) quartiles of the data distribution, whisker ends represent the lowest and the highest data point within the 1.5 interquartile range of the lower and the upper quartile, respectively. Seven larvae were released per pot

\section{Discussion}

We applied M. brunneum-FCBKs to pot substrates in late summer, together with planting of spring oat as a cover crop, and assessed the abundance of Metarhizium colonies and the recapture, survival and mycosis of wireworms released into pots. FCBK treatments significantly increased the abundance of Metarhizium colonies six weeks after treatment. Native Metarhizium colonies were also detected in all substrates, including those of the untreated control and the insecticide treatment. The presence of eight native Metarhizium genotypes in a rather limited number of samples showed that Metarhizium fungi were not only 


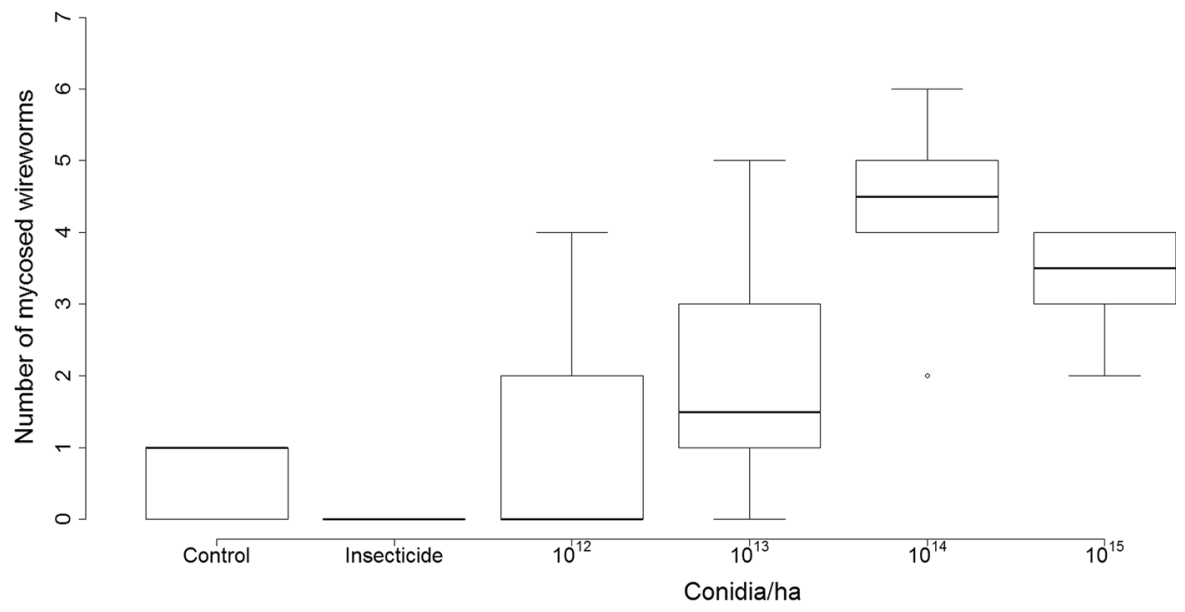

Fig. 3 Number of A. obscurus larvae with Metarhizium infection in November 2013, re-captured from pots four weeks after release and incubated individually in peat-filled cups for another six weeks. Boxes show the 1st (bottom line), 2nd (median, bold line), and 3rd (top line) quartiles of the data distribution, whisker ends represent the lowest and the highest data point within the 1.5 interquartile range of the lower and the upper quartile, respectively. Seven larvae were released per pot

Table 4 Origin and genotype of the 40 Metarhizium isolates obtained from mycosed cadavers and substrate samples collected six weeks (first evaluation date) and 32 weeks (second evaluation date) after application, respectively

\begin{tabular}{|c|c|c|c|c|}
\hline Treatment & Evaluation date & Number of colonies from cadavers & Number of colonies from substrate & $\begin{array}{l}\text { Genotypes } \\
\text { detected }\end{array}$ \\
\hline \multirow[t]{2}{*}{ Control } & 1 & 4 & - & $\mathrm{C}, \mathrm{D}, \mathrm{E}(\times 2)$ \\
\hline & 2 & - & 5 & $\mathrm{~A}, \mathrm{~B}, \mathrm{~F}, \mathrm{G}, \mathrm{H}$ \\
\hline \multirow[t]{2}{*}{ Insecticide } & 1 & - & - & - \\
\hline & 2 & - & 4 & $\mathrm{~A}, \mathrm{~B}(\times 2), \mathrm{I}$ \\
\hline FCBK 1 & 1 & 2 & - & A \\
\hline $10^{12}$ conidia ha ${ }^{-1}$ & 2 & - & - & - \\
\hline FCBK 2 & 1 & 5 & - & A \\
\hline $10^{13}$ conidia ha ${ }^{-1}$ & 2 & 4 & - & A \\
\hline FCBK 3 & 1 & 8 & - & A \\
\hline $10^{14}$ conidia ha $^{-1}$ & 2 & 3 & - & A \\
\hline FCBK 4 & 1 & 5 & - & A \\
\hline $10^{15}{\text { conidia } \mathrm{ha}^{-1}}^{-1}$ & 2 & - & - & - \\
\hline
\end{tabular}

FCBK 1-4 treatments with fungus colonized barley kernels; "-"= not evaluated; the FCBK production strain, Metarhizium brunneum ART2825, is designated as genotype A

abundant, but also genetically diverse in the field soil used for the experiment (see Table 4, supplementary Table S1). Similar abundance and diversity of $M e$ tarhizium spp. has been reported for soils of different habitats and geographical regions around the world (Steinwender et al. 2014; Enkerli et al. 2016; Kepler et al. 2015; Castro et al. 2016).

Metarhizium strains were re-isolated from about one third of the wireworm cadavers recovered from
FCBK treatments. All were genetically identical to the applied strain, ART2825 (Table 4). Four Metarhizium strains re-isolated from cadavers of control pots, however, were genetically different from ART2825, showing that several naturally occurring Metarhizium genotypes may have competed for the host resource. Nonetheless, the applied strain ART2825 was the preferential source of infection, which may indicate its competitiveness, or simply be a consequence of the 
large number of conidia applied. The incidence of the strain ART2825 in the substrate samples from untreated controls and the insecticide treatment may be of natural origin, since the strain was originally isolated from the region of the study.

Several studies indicate that a sufficient amount of EPF inoculum for insect pest control ranges from $10^{5}$ to $10^{6}$ CFUs per gram of soil (Bruck 2005; Ekesi et al. 2002; Ferron 1981; McDowell et al. 1990). Based on these data, Jaronski (2010) estimated $10^{14}-10^{15}$ conidia per hectare as the required dose for broadcast application and incorporation to a depth of $10 \mathrm{~cm}$. We reached this level of CFUs per gram of substrate with the highest dose applied $\left(10^{15}\right.$ conidia ha $\left.{ }^{-1}\right)$, which reduced wireworm survival in our experiment. A similar effect on wireworm survival was also achieved with a ten times lower application rate, which suggests that $10^{4}$ Metarhizium CFU per gram of soil may already provide a sufficient level of wireworm control (Figs. 2, 3). Furthermore, improved application methods may also help to reduce application rates. Jaronski (2010) proposed up to a 100-fold reduction of the field application rates by the use of banded instead of broadcast application of Metarhizium conidia against sugar beet root maggot. A similar strategy may be tested by applying FCBKs and sowing of the cover crop in strips. Furthermore, a switch from Metarhizium formulated as corn grit granules to recently developed microsclerotia of Metarhizium enables a reduction of field application rates by a factor of eight (Jaronski 2010; Jaronski and Jackson 2008).

Our results confirmed the persistence of M. brunneum conidia for up to eight months, without being affected by winter conditions. Therefore, an application of FCBKs into the cover crop several months before planting of potatoes in the main season should provide for an extended exposure period of the pest insects to the fungus. Wireworms typically show seasonal migration between upper and lower soil layers, depending on their moulting and feeding cycles, but also on environmental conditions in upper soil layers (reviewed in Traugott et al. 2015). The combination of these factors results in two activity "peaks" of many semivoltine wireworm species in the northern hemisphere, during which they are more frequently found in the topsoil near the soil surface. One occurs in March or April, after hibernation, and a second in in August or September, after the dry season. Consequently, application of the EPF into a cover crop in late summer, and persistence of conidia over winter, should allow the pest population to be targeted twice. However, we were not able to detect a further decrease in wireworm survival rates at the second evaluation date, 30 weeks after release. One explanation may be that the second evaluation was performed too early. Wireworms may still have been burrowed in lower layers of the pot substrates for hibernation, without having come into sufficient contact with conidia for a second time.

It has been shown that lower temperatures slow down fungal infections of wireworms (Kabaluk and Ericsson 2007). Accordingly, an EPF application during summertime in the northern hemisphere, as performed in our experiment, should promote fungal growth and efficacy. During this period, however, upper soil layers may suffer desiccation, which may affect viability of conidia beneath the soil surface. A green plant cover, as provided by spring oat in our experiment, might mitigate such drought stress and foster persistence of the fungus. There is evidence in the literature that the abundance of Metarhizium is higher in soils with a dense plant cover, like grasslands or field margins (Keller et al. 2003; Schneider et al. 2012). There are, however, many factors that would contribute to making such habitats a favourable environment, including microclimatic and edaphic factors, as well as a better supply of potential host insects, less input of fungicides and herbicides and less disturbance by soil cultivation (Jaronski 2007; Keller et al. 2003). Their complex interactions are still not understood and need to be further investigated (Jaronski 2007; Schneider et al. 2012).

The combined application of the entomopathogenic fungus together with the cover crop may also constitute a simple, yet effective "attract and kill" strategy. Carbon dioxide is emitted from germinating seeds and other plant tissues, and $\mathrm{CO}_{2}$ gradients are therefore a basic means of orientation of insect larvae towards potential food sources (Doane et al. 1975; Klingler 1957). These gradients have been shown to influence the vertical migrations of wireworms in soil (Jung et al. 2014; Sonnemann et al. 2014). In our experimental set-up, the germinating oat seedlings also produced $\mathrm{CO}_{2}$, and potentially attracted wireworms into conidia-contaminated soil layers. Current research has investigated this means of orientation as part of an "attract and kill" strategy in several ways. Schumann et al. (2013, 2014) lured western corn rootworm (Diabrotica virgifera virgifera LeConte, 
Coleoptera: Chrysomelidae) larvae to an insecticide or to a microbial control agent with the help of artificial $\mathrm{CO}_{2}$ sources. Vernon et al. (2016) sowed insecticidetreated wheat as a lethal trap crop for wireworms into furrows at potato planting. The $\mathrm{CO}_{2}$ released from germinating seeds and/or wheat roots attracted wireworms and facilitated contact with the insecticide.

In conclusion, high concentrations of M. brunneum conidia caused significant wireworm mortality in our pot experiment, after an incubation period of about one to two months. M. brunneum conidia persisted in the substrate for up to eight months. Spring oat as a cover crop on treated substrates may have provided favourable conditions for fungal persistence. Contrary to expectations, however, this did not lead to a further decrease in wireworm survival rates between the first and the second evaluation date. It remains to be shown if an extended period of exposure of wireworms to Metarhizium conidia has the potential to increase efficacy of the biocontrol treatment, and thus facilitate the reduction of field application rates.

Acknowledgements This work was part of the project "INBIOSOIL", funded by the 7th framework program of the European Union (Grant-ID: 282767). We thank Christian Schweizer, Agroscope, Zurich, for technical assistance and Russell Naisbit, Albion Science Editing, Neuchâtel, for correcting the English. We also appreciate the constructive criticism of two anonymous reviewers on an earlier version of the manuscript.

Open Access This article is distributed under the terms of the Creative Commons Attribution 4.0 International License (http:// creativecommons.org/licenses/by/4.0/), which permits unrestricted use, distribution, and reproduction in any medium, provided you give appropriate credit to the original author(s) and the source, provide a link to the Creative Commons license, and indicate if changes were made.

\section{References}

Ansari MA, Evans M, Butt TM (2009) Identification of pathogenic strains of entomopathogenic nematodes and fungi for wireworm control. Crop Prot 28:269-272

Aregger E (1992) Conidia production of the fungus Beauveria brongniartii on barley and quality evaluation during storage at $2{ }^{\circ} \mathrm{C}$. J Invertebr Pathol 59:2-10

Barsics F, Haubruge E, Verheggen J (2013) Wireworms' management: an overview of the existing methods, with particular regards to Agriotes spp. (Coleoptera: Elateridae). Insects 4:117-152

Bates D, Maechler M, Bolker B, Walker S (2015) Fitting linear mixed-effects models using lme4. J Stat Softw 67(1):1-48
Bruck DJ (2005) Ecology of Metarhizium anisopliae in soilless potting media and the rhizosphere: implications for pest management. Biol Control 32:155-163

Castro T, Mayerhofer J, Enkerli J, Eilenberg J, Meyling N, de Andrade Moral R, Garcia Borges Demétrio C, Delalibera I Jr (2016) Persistence of Brazilian isolates of the entomopathogenic fungi Metarhizium anisopliae and $M$. robertsii in strawberry crop soil after soil drench application. Agric Ecosyst Environ 233:361-369

Doane JF, Lee YW, Klingler J, Westcott ND (1975) Orientation response of Ctenicera destructor and other wireworms (Coleoptera: Elateridae) to germinating grain and to carbon dioxide. Can Entomol 107:1233-1252

Eckard S, Ansari MA, Bacher S, Butt TM, Enkerli J, Grabenweger $\mathrm{G}$ (2014) Virulence of in vivo and in vitro produced conidia of Metarhizium brunneum strains for control of wireworms. Crop Prot 64:137-142

Ekesi S, Maniania NK, Lux SA (2002) Mortality in three African tephritid fruit fly puparia and adults caused by the entomopathogenic fungi, Metarhizium anisopliae and Beauveria bassiana. Biocontrol Sci Techn 12:7-17

Enkerli J, Widmer F, Gessler C, Keller S (2001) Strain-specific microsatellite markers in the entomopathogenic fungus Beauveria brongniartii. Mycol Res 105:1079-1087

Enkerli J, Kölliker R, Keller S, Widmer F (2005) Isolation and characterization of microsatellite markers from the entomopathogenic fungus Metarhizium anisopliae. Mol Ecol Notes 5:384-386

Enkerli J, Schneider S, Mayerhofer J, Huang Z, Sundh I, Vidal S, Widmer F (2016) Genetic diversity of Metarhizium spp. in grass, wheat, and forest habitats. 49th annual meeting of the society for invertebrate pathology, Tours, France, July 24th-28th

Ester A, Huiting H (2007) Controlling wireworms (Agriotes spp.) in a potato crop with biologicals. IOBC/WPRS Bull 30:189-196

Ferron P (1981) Pest control by the fungus Beauveria and Metarhizium. In: Burges HD (ed) Microbial control of pests and plant diseases 1970-1980. Academic Press, London, pp 465-482

Fisher JR, Keaster AJ, Fairchild ML (1975) Seasonal vertical movement of wireworm larva in Missouri-influence of soil temperature on genera Melanotus Eschscholtz and Conoderus Eschscholtz. Ann Entomol Soc Am 68:10711073

Furlan L (1998) The biology of Agriotes ustulatus Schäller (Col., Elateridae). II. Larval development, pupation, whole cycle description and practical implications. J Appl Entomol 122:71-78

Furlan L (2004) The biology of Agriotes sordidus Illiger (Col., Elateridae). J Appl Entomol 128:696-706

Jaronski ST (2007) Soil ecology of the entomopathogenic ascomycetes: a critical examination of what we (think) we know. In: Ekesi S, Maniania NK (eds) Use of entomopathogenic fungi in biological pest management. Research Signpost, Kerala, pp 91-143

Jaronski ST (2010) Ecological factors in the inundative use of fungal entomopathogens. BioControl 55:159-185

Jaronski ST, Jackson MA (2008) Efficacy of Metarhizium anisopliae microsclerotial granules. Biocontrol Sci Technol 18:849-863 
Jedlička P, Frouz J (2007) Population dynamics of wireworms (Coleoptera, Elateridae) in arable land after abandonment. Biologia 62:103-111

Jossi W (2001) Drahtwürmer im jahr vor kartoffelanbau bekämpfen. UFA-Revue 7-8(2001):44-46

Jung J, Racca P, Schmitt J, Kleinhenz B (2014) SIMAGRIO-W: development of a prediction model for wireworms in relation to soil moisture, temperature and type. J Appl Entomol 138:183-194

Kabaluk T (2007) Promise versus performance: working toward the use of Metarhizium anisopliae as a biological control for wireworms. IOBC/WPRS Bull 30:69-77

Kabaluk JT, Ericsson JD (2007) Environmental and behavioral constraints on the infection of wireworms by Metarhizium anisopliae. Environ Entomol 36:1415-1420

Kabaluk JT, Goettel MS, Erlandson M, Ericsson JD, Duke G, Vernon B (2005) Metarhizium anisopliae as a biological control for wireworms and a report of some other naturallyoccurring parasites. IOBC/WPRS Bull 28:109-115

Keller S, Kessler P, Schweizer C (2003) Distribution of insect pathogenic soil fungi in Switzerland with special reference to Beauveria brongniartii and Metarhizium anisopliae. BioControl 48:307-319

Kepler RM, Ugine TA, Maul JE, Cavigelli MA, Rehner SA (2015) Community composition and population genetics of insect pathogenic fungi in the genus Metarhizium from soils of a long term agricultural research system. Environ Microbiol 17:2791-2804

Kessler P, Matzke H, Keller S (2003) The effect of application time and soil factors on the occurrence of Beauveria brongniartii applied as a biological control agent in soil. J Invertebr Pathol 84:15-23

Klausnitzer B (1994) Family Elateridae. In: Klausnitzer B (ed) Die larven der käfer Mitteleuropas, vol 2. Goecke and Evers, Krefeld, pp 118-189

Kleespies R, Ritter C, Zimmermann G, Burghause F, Feiertag S, Leclerque A (2013) A survey of microbial antagonists of Agriotes wireworms from Germany and Italy. J Pest Sci 86:89-106

Klingler J (1957) Über die bedeutung des kohlendioxyds für die orientierung der larven von Otiorrhynchus sulcatus F., in Melolontha und Agriotes (Col.) im boden. Mitt Schweiz Entomol Ges 31:317-322

Kölliker U, Jossi W, Kuske S (2009) Optimised protocol for wireworm rearing. IOBC/WPRS Bull 45:457-460

Kölliker U, Biasio L, Jossi W (2011) Potential control of Swiss wireworms with entomopathogenic fungi. IOBC/WPRS Bull 66:517-520

Ladurner E, Quentin U, Franceschini S, Benuzzi M (2009) Efficacy evaluation of the entomopathogenic fungus Beauveria bassiana strain ATCC 74040 against wireworms (Agriotes spp.) on potato. IOBC/WPRS Bull 45:445-448

McDowell JM, Funderburk JE, Boucias DG, Gilreath ME, Lynch RE (1990) Biological activity of Beauveria bassiana against Elasmopalpus lignosellus (Lepidoptera: Pyralidae) on leaf substrates and soil. Environ Entomol 19:137-141

Oulevey C, Widmer F, Kölliker R, Enkerli J (2009) An optimized microsatellite marker set for detection of $\mathrm{Me}$ tarhizium anisopliae genotype diversity on field and regional scales. Mycol Res 113:1016-1024
Parker WE, Howard JJ (2001) The biology and management of wireworms (Agriotes spp.) on potato with particular reference to the U.K. Agric For Entomol 3:85-98

Pilz C, Enkerli J, Wegensteiner R, Keller S (2010) Establishment and persistence of the entomopathogenic fungus Metarhizium anisopliae in maize fields. J Appl Entomol 135:393-403

R Development Core Team (2016) R: a language and environment for statistical computing. R Foundation for Statistical Computing, Vienna, Austria. https://www.R-project.org

Riba G, Bouvier-Fourcade I, Caudal A (1986) Isoenzymes polymorphism in Metarhizium anisopliae (Deuteromycotina: Hyphomycetes) entomogenous fungi. Mycopathologia 96:161-169

Ritter C, Richter E (2013) Control methods and monitoring of Agriotes wireworms (Coleptera: Elateridae). J Plant Dis Prot 120:4-15

Schaerffenberg B (1942) Der einfluß von humusgehalt und feuchtigkeit des bodens auf die fraßtätigkeit der elateridenlarven. Anz Schädl 18:133-136

Schielzeth H (2010) Simple means to improve the interpretability of regression coefficients. Methods Ecol Evol 1(2):103-113

Schneider S, Widmer F, Jacot K, Kölliker R, Enkerli J (2012) Spatial distribution of Metarhizium clade 1 in agricultural landscapes with arable land and different semi-natural habitats. Appl Soil Ecol 52:20-28

Schumann M, Patel A, Vidal S (2013) Evaluation of an attract and kill strategy for western corn rootworm larvae. Appl Soil Ecol 64:178-189

Schumann M, Patel A, Vidal S (2014) Soil application of an encapsulated $\mathrm{CO}_{2}$ source and its potential for management of western corn rootworm larvae. J Econ Entomol 107:230-239

Sonnemann I, Grunz S, Wurst S (2014) Horizontal migration of click beetle (Agriotes spp.) larvae depends on food availability. Entomol Exp Appl 150:174-178

Steinwender BM, Enkerli J, Widmer F, Eilenberg J, ThorupKristensen K, Meyling NV (2014) Molecular diversity of the entomopathogenic fungal Metarhizium community within an agroecosystem. J Invertebr Pathol 123:6-12

Strasser H, Forer A, Schinner F (1996) Development of media for the selective isolation and maintenance of virulence of Beauveria brongniartii. In: Glare TR, Jackson TA (eds) Microbial control of soil dwelling pests. AgResearch, Lincoln, pp 125-130

Sufyan M, Neuhoff D, Furlan L (2014) Larval development of Agriotes obscurus under laboratory and semi-natural conditions. Bull Insectology 67:227-235

Traugott M, Schallhart N, Staudacher K, Wallinger C (2013) Understanding the ecology of wireworms and improving their control: a special issue. J Pest Sci 86:1-2

Traugott M, Benefer CM, Blackshaw RP, van Herk WG, Vernon RS (2015) Biology, ecology, and control of elaterid beetles in agricultural land. Annu Rev Entomol 60:313-334

Vernon RS, van Herk WG (2013) Wireworms as pests of potato. In: Giordanengo P, Vincent C, Alyokhin A (eds) Insect pests of potato: global perspectives on biology and management. Academic, Amsterdam, pp 103-164

Vernon RS, van Herk W, Tolman J, Saavedra HO, Clodius M, Gage B (2008) Transitional sublethal and lethal effects of insecticides after dermal exposures to five economic 
species of wireworms (Coleoptera: Elateridae). J Econ Entomol 101:365-374

Vernon RS, van Herk WG, Clodius M, Harding C (2009) Wireworm management I: stand protection versus wireworm mortality with wheat seed treatments. J Econ Entomol 102:2126-2136

Vernon RS, van Herk WG, Clodius M, Harding C (2013) Crop protection and mortality of Agriotes obscurus wireworms with blended insecticidal wheat seed treatments. J Pest Sci 86:137-150

Vernon RS, van Herk WG, Clodius M, Tolman J (2016) Companion planting attract-and-kill method for wireworm management in potatoes. J Pest Sci 89:375-389

Sina Alexandra Rogge evaluated the preventive application of an entomopathogenic fungus as a biocontrol agent against wireworms in her master thesis.
Johanna Mayerhofer investigates potential effects of the application of insect pathogenic fungi on microbial communities in pest control.

Jürg Enkerli, supervisor of Johanna Mayerhofer, is a molecular biologist at Agroscope studying ecological aspects and diversity of insect pathogenic fungi.

Sven Bacher is an applied ecologist at the University of Fribourg with expertise in the fields of biological invasions and pest control.

Giselher Grabenweger, supervisor of Sina Rogge, investigates the potential of entomopathogenic fungi as biocontrol agents of agricultural pests at Agroscope, the Swiss Federal Institute for agricultural research. 